\title{
Inventory Policy Determination for Raw Materials in ILY Pharmaceutical using Periodic Review (R, S, S) and Periodic Review (R, S) Method to Minimize Total Inventory Cost
}

\author{
Puteri Mely Permatasari ${ }^{1, *}$, Ari Yanuar Ridwan ${ }^{1}$, and Budi Santosa ${ }^{1}$ \\ ${ }^{1}$ Industrial Engineering, Telkom University, Bandung, Indonesia
}

\begin{abstract}
ILY Pharmaceutical is one of the pharmaceutical industry in Bandung that produces various type of medicines. In managing the raw materials for production, ILY Pharmaceutical is not using any standardize calculation for the inventory policy of the raw materials. That condition caused the raw materials to be overstocked and made the total inventory cost to be higher. The objective of this research is to minimize the total inventory cost in ILY Pharmaceutical by giving an inventory policy proposal. Based on the classification of the raw materials using $A B C$ analysis, two inventory policy will be used. Periodic review (R, s, S) for A category and periodic review $(\mathrm{R}, \mathrm{S})$ for B and C category. The proposed inventory policy able to reduce the total inventory cost by $42 \%$ from $\$ 12.194,98$ to $\$ 7.029,29$. The reduced cost is mainly caused by the quantity of the raw materials that is stored in the warehouse is smaller than the existing condition. Even though the frequency of the order is increased thus increasing the order cost but the quantity ordered is smaller because in the proposed condition, there are a maximum inventory level so, the quantity ordered cannot exceed that level.
\end{abstract}

\section{Introduction}

ILY Pharmaceutical is an industry in Bandung that produces various type of medicines such as caplet, tablet, capsule, dry syrup, syrup and external medicine fluids. The medicines then will be distributed to fulfil the demands of all health units associated with Indonesian Army all over Indonesia. One of the problems faced by ILY Pharmaceutical is regarding the inventory of raw materials. The stock of raw materials is always bigger than the demand thus causing overstock of the materials. ILY Pharmaceutical is procuring the raw materials quarterly and always order the raw materials in bulk to the supplier to cope with the fluctuating demand of the raw materials. Up until now, ILY Pharmaceutical does not have an exact calculation for the reorder point and maximum inventory level that is needed to help managing the inventory of raw materials in the warehouse. So, the raw materials ordered is done merely on the hunch of the personnel or when there is a stock out. This

\footnotetext{
*Corresponding author: puterimely@gmail.com
} 
conditions then further caused the inventory of raw materials to be out of control. Fig. 1 shows that the gap of stock and demand of the raw materials is very wide.

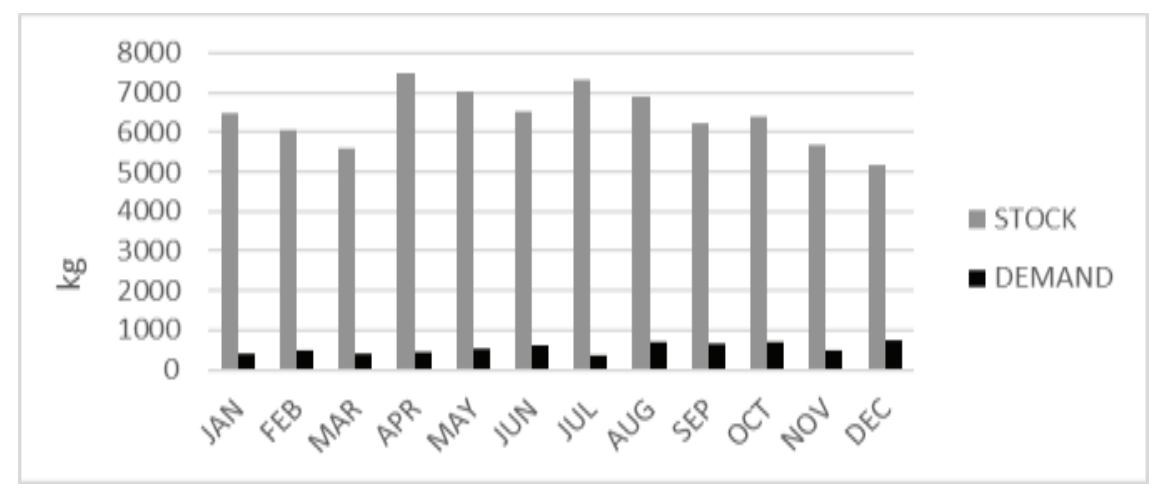

Fig. 1. Comparison of Raw Materials Stock and Demand in 2016

The overstock condition can further cause of loss to the company because it can make the holding cost higher. Furthermore, the probability of the raw materials that will be expired before used will be higher also. The expired materials will bring negative to the company because the materials cannot be stock anymore and must be disposed. In 2016, the total inventory cost has reached $\$ 12.194$. The overstock conditions then must be solved so the raw materials inventory can be well controlled and the total inventory cost can be minimized as well. Therefore, further research is needed to solve the problem by using inventory policy that will help determining the policy for the raw materials. So, the objective of this research is to minimize the total inventory cost in ILY Pharmaceutical by giving an inventory policy proposal.

\section{Inventory Policy}

Inventory is defined as an idle resource which waiting for further process such as production in manufacture system, marketing activity in distribution system or consumption activity in household, office etc. [1]. Inventory is helpful to anticipate the supply and demand uncertainty [2]. Based on the value addition or stage of completion, inventory can be classified into three types, which are raw materials, work-in-progress, and finished good [1]. In determining the inventory policy, there are some relevant cost that can be classified into four categories which are procurement costs, inventory holding costs, shortage costs, and obsolescence costs [3].

The items that are managed in the inventory can be classified based on the investment level in one period [4,5]. The classification is done using $\mathrm{ABC}$ Analysis. Using $\mathrm{ABC}$ Analysis, the items will be classified into category A, B, and C. Based on the classification results then the inventory policy that can be used are as follows [5]:

Table 1. Inventory Policy

\begin{tabular}{ccc}
\hline Category & $\begin{array}{c}\text { Continuous } \\
\text { Review }\end{array}$ & $\begin{array}{c}\text { Periodic } \\
\text { Review }\end{array}$ \\
\hline A & $(\mathrm{s}, \mathrm{S})$ & $(\mathrm{R}, \mathrm{s}, \mathrm{S})$ \\
$\mathrm{B}$ & $(\mathrm{s}, \mathrm{Q})$ & $(\mathrm{R}, \mathrm{S})$ \\
\hline
\end{tabular}


For the C category, the usual EOQ or the same inventory as category B can be used [5]. In this research, periodic review inventory policy will be used.

The previous research conducted by Dayanti [6] shows that by classifying the raw materials using $\mathrm{ABC}$ Analysis and then use different inventory policy based on the category resulting in a lower total inventory cost. A category is using continuous review ( $\mathrm{s}, \mathrm{S})$ while the $\mathrm{B}$ and $\mathrm{C}$ category is using continuous review ( $\mathrm{s}, \mathrm{Q})$. Other research conducted by Arismawati [7] regarding the inventory policy of accessories part by using periodic review $(\mathrm{R}, \mathrm{s}, \mathrm{S})$ shows that it can minimized the total inventory cost. Also, referencing from the research done by Merdalina [8], by using two periodic review policy of $(R, s, S)$ and $(R, S)$ can minimize the total inventory cost of the lubricant oil in PT. NYZ. From the previous research, it shown that both the continuous and periodic review policy can minimize the total inventory cost.

To compare between the continuous and periodic review policy, Setyaningsih [9] conducted a research in Public Hospital Bandung. The results shown that both the continuous and periodic review has their own advantages and disadvantages. Due to the characteristic of the items which has a low demand and low price the periodic review policy gave a lower total inventory cost than the continuous review.

\section{Research Methodology}

The data needed for this research were collected by doing observation and interview with the personnel in ILY Pharmaceutical. The data collected in this research are lead time, holding cost, order cost, shortage cost and raw materials demand. The data then used for calculating the parameter of the inventory policy. The total inventory cost of the proposed inventory policy then will be compared with the existing total inventory cost to see whether the proposed condition is better or not. The steps to solved the problem is described in conceptual model. Research methodology explains about the relationship between variables and the method that support the research and can be seen in Fig 2.

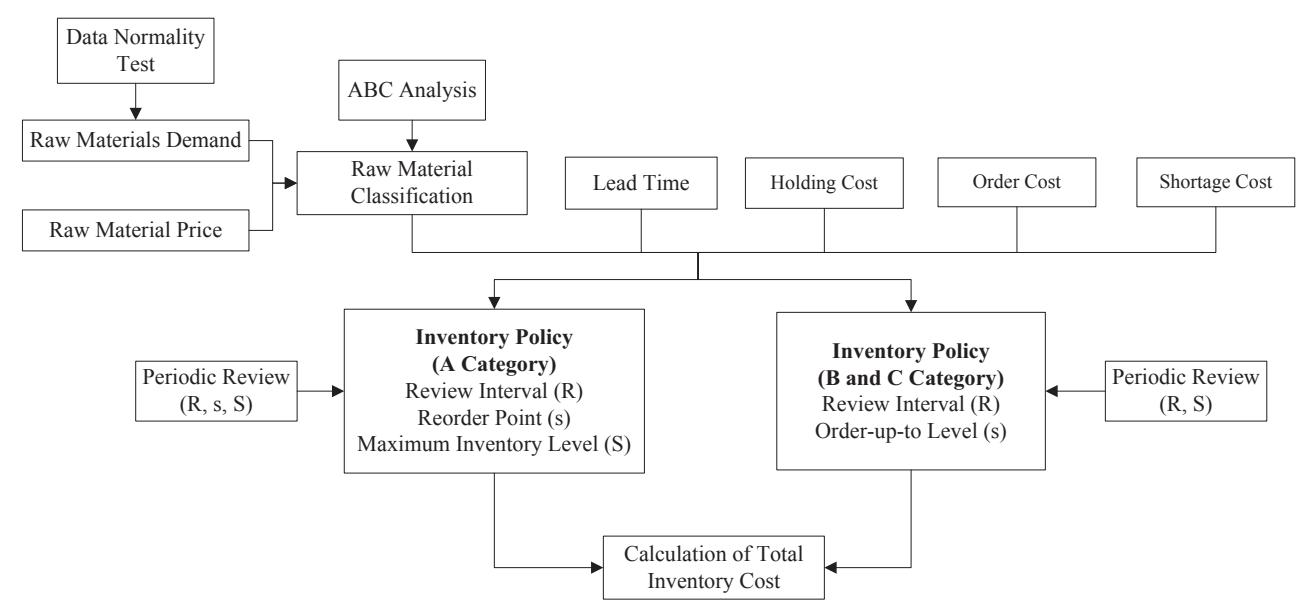

Fig. 2. Research Methodology

Looking at the previous research and the existing condition of ILY Pharmaceutical that is reviewing and procuring the raw materials quarterly so, in this research, periodic review $(\mathrm{R}, \mathrm{s}, \mathrm{S})$ system and periodic review $(\mathrm{R}, \mathrm{S})$ system is suitable to be used for the proposed inventory policy. Periodic review $(\mathrm{R}, \mathrm{s}, \mathrm{S})$ is when the inventory level at or below s then the 
replenishment is done until it reaches the maximum inventory level (S) for every R period. If the inventory level is above $\mathrm{s}$, then there is no ordering even though it already reaches $\mathrm{R}$ period. The algorithm formulation for calculating the reorder point (s) and maximum level (S) are as follows [5]:

The first step is calculating $Q_{p}$ and $S_{p}$ value.

$$
\begin{gathered}
Q_{p}=1,3\left(B_{3}{ }^{0,494}\right)(A / v r)^{0,506}\left[1+\left(\sigma_{R+L}^{2} / x_{\text {bar }}{ }^{2}\right)\right]^{0,016} \\
S_{p}=[0,973(R+L) D]+\left\{\sigma_{R+L}[(0,183 / z)+1,603-(2,192 z)\}\right.
\end{gathered}
$$

Where,

$$
z=\sqrt{ }\left(Q_{p} r\right) /\left(B_{3}\right)
$$

Step 2. If $Q_{p} / x_{\text {barR }}>1,5$ then s and $\mathrm{S}$ can be obtained by:

$$
\begin{gathered}
s=S_{p} \\
S=S_{p}+Q_{p}
\end{gathered}
$$

If $Q_{p} / x_{\text {barR }}<1,5$ then continue to the next step.

$$
P_{\mu}(k)=r /\left(B_{3}+r\right)
$$

Where the value of $k$ is obtained from the table.

$$
S_{0}=x_{b a r(R+L)}+k \sigma_{R+L}
$$

Calculate the reorder point (s) and maximum stock (S)

$$
\begin{gathered}
S=\operatorname{minimum}\left\{S_{p}, S_{0}\right\} \\
S=\text { minimum }\left\{S_{p}, Q_{p}+S_{0}\right\}
\end{gathered}
$$

Notations,

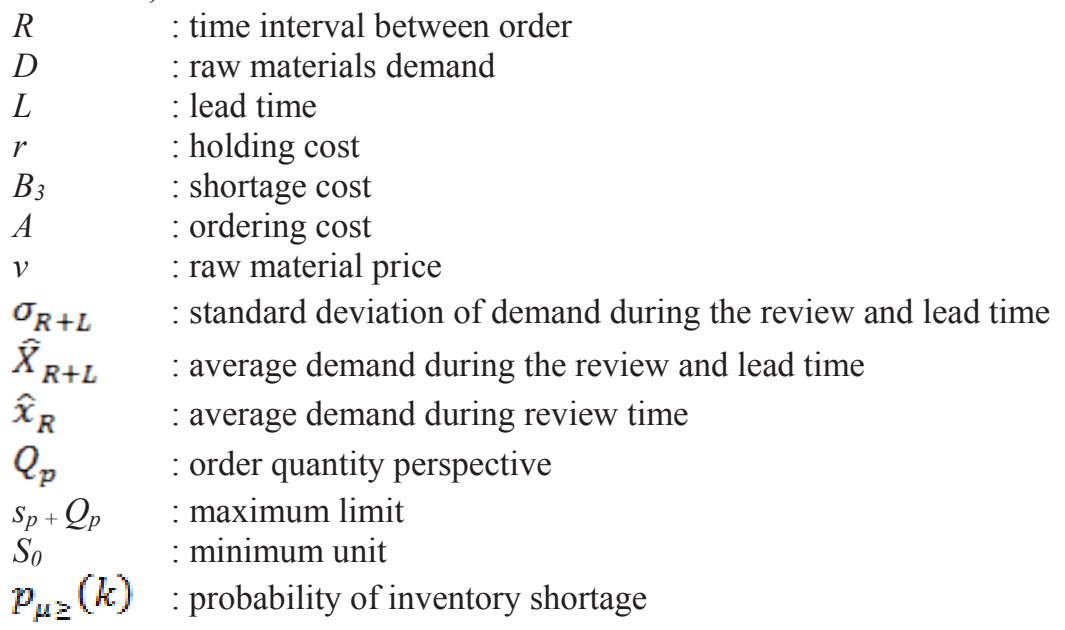


In periodic review $(\mathrm{R}, \mathrm{S})$, the order is done in every $\mathrm{R}$ period to increase the inventory level up to $\mathrm{S}$. The calculation for $(\mathrm{R}, \mathrm{S})$ is almost the same with $(\mathrm{s}, \mathrm{Q})$ but with some transformation [5]. The transformation are as follows:
$(\mathrm{s}, \mathrm{Q})$
$(\mathrm{R}, \mathrm{S})$
S S
Q DR
L $\quad \mathrm{R}+\mathrm{L}$
Calculate,

$$
G u(k)=\left(x_{b a r(R+L) /} \sigma_{R+L}\right)\left(r / r B_{3}\right)
$$

Where,

$$
S=x_{\operatorname{bar}(R+L}+k \sigma_{R+L}
$$

\section{Results and Discussion}

\subsection{ABC Analysis}

The ABC analysis classify the raw materials into three categories which are A, B, and C. From the analysis, from a total of 54 items, there were 12 items in A category, 11 items in B category and 31 items in $\mathrm{C}$ category. The inventory policy of every items then will be calculated based on the category. The review period is predefined which is 3 months.

\subsection{Periodic Review (R, s, S)}

After the classification, the parameter of periodic review (R, s, S) and periodic review (R, $\mathrm{S})$ are calculated. In Periodic Review $(\mathrm{R}, \mathrm{s}, \mathrm{S})$, the parameter that will be calculated is the reorder point (s) which is the where the order will be done if the inventory level is below that point. The second parameter is the maximum inventory level. The raw materials that will be calculated using this system is the A item. The calculation of Periodic Review (R, s, S) for raw materials MAT25 will be used as a sample calculation. It is known that:

$$
\begin{array}{ll}
\mathrm{R} & =3 \text { months, } \\
\mathrm{L} & =1 \text { month } \\
\mathrm{D} & =57,543 \mathrm{~kg} / \text { year}, \\
\sigma & =2,19 \mathrm{~kg}, \\
\mathrm{~V} & =\$ 188,03 / \mathrm{kg}, \\
\mathrm{A} & =\$ 1,96 / \mathrm{order} \\
\mathrm{R} & =\$ 2,05 / \mathrm{unit} / \text { year}, \\
\mathrm{B} 3 & =\$ 11,36 / \mathrm{kg} \text { short. }
\end{array}
$$

From the calculation using the equation (1) to (8), it is obtained that the reorder point (s) of MAT25 is $19,831 \mathrm{~kg}$ and the maximum stock $(\mathrm{S})$ is $19,926 \mathrm{~kg}$.

\subsection{Periodic Review (R, S)}

In Periodic Review (R, S), the order will be done every R period to make the inventory level reach the up-to-level $\mathrm{S}$ again. The raw materials that will be calculated using this system is the B and C item. The calculation of Periodic Review $(\mathrm{R}, \mathrm{S})$ for raw materials MAT01 will be used as a sample calculation. It is known that:

$$
\begin{array}{ll}
\mathrm{R} & =3 \text { months, } \\
\mathrm{L} & =1 \text { month, } \\
\mathrm{D} & =98,245 \mathrm{~kg} / \text { year, } \\
\sigma & =6,958 \mathrm{~kg},
\end{array}
$$


$\mathrm{r} \quad=\$ 2,05 /$ unit/year,

B3 $=\$ 2,86 / \mathrm{kg}$ short.

From the calculation using the equation (9) and (10), it is obtained that the order-up-tolevel of MAT01 is $65,497 \mathrm{~kg}$.

\subsection{Total Inventory Cost}

From the determination of periodic review $(\mathrm{R}, \mathrm{s}, \mathrm{S})$ and periodic review $(\mathrm{R}, \mathrm{S})$ inventory policy, the existing and proposed cost then will be calculated and compared.

Table 3. Total Inventory Cost

\begin{tabular}{|c|c|c|}
\hline Category & Existing & Proposal \\
\hline Order Cost & $\$ 12.087,10$ & $\$ 6.605,64$ \\
\hline Holding Cost & $\$ 107,88$ & $\$ 423,65$ \\
\hline Shortage Cost & $\$-$ & $\$-$ \\
\hline Total Inventory Cost & $\$ 12.194,98$ & $\$ 7.029,29$ \\
\hline
\end{tabular}

The proposed inventory policy has given a lower holding cost than the existing condition. The proposed inventory policy reduces the cost by $45 \%$. The reduced cost is caused by the quantity of the raw materials kept in the warehouse is smaller than the existing condition. Furthermore, the quantity of the raw material that is purchased is smaller because in the proposed inventory policy, the maximum inventory level and the reorder point is determined so, ILY Pharmaceutical only done the replenishment if the inventory level has reached or below the reorder point and only replenished it up to the maximum inventory level.

The proposed inventory policy increase the order cost by $293 \%$ that was caused by the total order frequency of the raw materials was more than the existing condition. In the existing condition the replenishment for the raw materials is not done frequently but with a big quantity while in the proposed inventory policy, the order is done almost in every period but with smaller quantity.

Both the existing and proposed condition shows that there is no raw material shortage. The proposed inventory policy shown that with determining the parameter of periodic review $(\mathrm{R}, \mathrm{s}, \mathrm{S})$ and periodic review $(\mathrm{R}, \mathrm{S})$, it can still fulfil the demand of the raw materials.

From the calculation results, it is obtained that by using periodic review (R, s, S) and periodic review $(\mathrm{R}, \mathrm{S})$, the inventory of the raw materials can be reduced because the item ordered is smaller in quantity.

\section{Conclusion}

The problem faced by ILY Pharmaceutical is the overstock of the raw materials that make a high total inventory cost. From the problem faced by ILY Pharmaceutical, this research then focused to minimize the total inventory cost in ILY Pharmaceutical by giving an inventory policy proposal. From the proposed inventory policy, the review period, maximum inventory level and reorder point were obtained. The proposed inventory policy able to reduce the total inventory cost by $42 \%$ from $\$ 12.194,98$ to $\$ 7.029,29$. The reduced cost is mainly caused by the quantity of the raw materials that is stored in the warehouse is smaller than the existing condition. Even though the frequency of the order is increased 
thus increasing the order cost but the quantity ordered is smaller because in the proposed condition, there are a maximum inventory level so, the quantity ordered cannot exceed that level.

\section{References}

1. S.N. Bahagia, Sistem Inventori, Bandung: Penerbit ITB (2006)

2. C. Bozarth, and R. Handfield, Introduction to Operations and Supply Chain Management (Pearson, 2008)

3. G. Ghiani, G. Laporte, and R. Musmanno, Introduction to Logistics Systems Planning and Control (John Wiley \& Sons Ltd, West Sussex, 2004)

4. R. Nadkarni, and A. Ghewari, International Journal of Engineering Business and Enterprise Application, 1, 24 (2016)

5. E.A. Silver, D.F. Pyke, and R. Peterson, Inventory Management and Production Planning and Scheduling (Wiley, New York, 1998)

6. S. Dayanti, A.Y. Ridwan, M.D. Astuti, Telkom University e-Proceeding of Engineering, 3, 2982 (2016)

7. P. Arismawati, A.Y. Ridwan, and B. Santosa, Telkom University e-Proceeding of Engineering, 2, 4877 (2015)

8. Merdalina. A.Y. Ridwan, and B. Santosa, Telkom University e-Proceeding of Engineering (2016)

9. S. Setyaningsih, and M. H. Basri, International Journal of Innovation Management and Technology, 4, 2 (2013)

10. M. Gebicki, E. Mooney, S. Chen, and L. M. Mazur. Health Care Manag Sci, 17, 215229 (2013) 